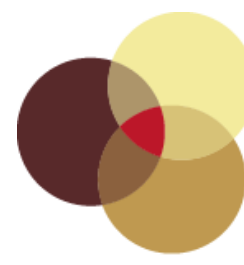

contennporaneity

Vol 7, No 1 (2018) ｜ＩSSN 2153-5914 (online) ｜ＤOI 10.5195/contemp/2018.262

http://contemporaneity.pitt.edu

\title{
Letícia Parente in Pacific Standard Time: LA/LA (Los Angeles/Latin America)
}

Paulina Pardo Gaviria

\section{Exhibition Review}

Exhibition schedule: Video Art in Latin America, LAXART, September 7-December 17, 2017.

Exhibition schedule: Xerografia: Copyart in Brazil, 1970-1990, Robert and Karen Hoehn Family Galleries, University of San Diego, September 15-December 16, 2017.

Exhibition schedule: Radical Women: Latin American Art, 1960-1985, Hammer Museum, University of California Los Angeles, September 15-December 31, 2017; Brooklyn Museum, April 13-July 22, 2018; Pinacoteca de São Paulo, August 18-November 19, 2018.

\section{About the Author}

Paulina Pardo Gaviria joined the history of art and architecture PhD program at the University of Pittsburgh in fall 2014 to specialize in art from Latin America. Her research examines the production of non-medium specific works (video, installation, Xerox- and mail-art) as developed in the Americas during the 1960s-1980s, interrogating how interdisciplinary visual strategies have redefined the art object. Focusing on the development of contemporary art from Brazil, her dissertation project is the first monographic approach to the work of Brazilian artist Letícia Parente (1930-1991). 


\section{Letícia Parente in Pacific Standard Time:}

\author{
LA/LA (Los Angeles/Latin America)
}

Paulina Pardo Gaviria
This review considers three separate exhibitions that were part of Pacific Standard Time: LA/LA (LOS Angeles/Latin America) for how their simultaneous showcase of works by Letícia Parente (Brazil, 19301991) effectively revealed multiple layers of meaning in her work, while acting as a through line between exhibitions. On view in the fall of 2017, across more than seventy Southern California institutions, $P S T: L A / L A$ was a large-scale Getty Foundation initiative of thematic exhibitions of art from Latin America that allowed multiple historical perspectives on art from the region. Mostly known in Brazil for Marca registrada (Trademark, 1975) - a ten-minute black-and-white video that records the artist sewing the inscription "MADE IN BRASIL" onto her own foot-Parente's oeuvre comprises videos, collages, installations, and mail and Xerox artworks mainly produced between 1974 and 1982, the final years of Brazil's 1964-1985 military dictatorship. ${ }^{1}$ The inclusion of Parente's work in three concurrent PST:LA/LA exhibitions demonstrated its historical relevance in approaching 1970s Latin American art through new media as well as the artist's responses to the recent violent history of the region and Brazil, in particular.

Video Art in Latin America, at the art space LAXART in Hollywood, and Xerografia: Copyart in Brazil, 1970-1990, at the University of San Diego's University Galleries, presented Parente as part of medium-specific art histories, emphasizing the centrality of novel technologies in her work. Video Art in Latin America underscored Parente's pioneering explorations of the artistic possibilities of the medium of video at a time when only few cameras were available to artists in Brazil-despite Sony's launch of the first portable recording camera in 1965. Meanwhile, Xerografia situated Parente within local networks of artists that used xerography and other industrial reproduction techniques to respond to the censorship apparatus, while reflecting on the value of the art object and the structures of the art world. In Radical Women: Latin American Art, 1960-1985, originally presented at the Hammer Museum in 2017 and traveling to two additional venues in 2018, Parente's videos were installed in dialogue with the works of 123 female artists working throughout the Americas during a politically convulsive period that saw the rise of feminist movements and the consolidation of radical artistic practices.

1 The first presentation of Letícia Parente's work in the United States was the installation of Medida (Measurement, 1976), which was part of Data (after)Lives: The Persistence of Encoded Identity (University of Pittsburgh Art Gallery, September 8-October 14, 2016). The online exhibition of Data (after)Lives: The Persistence of Encoded Identity is currently on view at the University Art Gallery website (http://uag.pitt.edu). For further information on this curatorial project, see Alison Langmead and Paulina Pardo Gaviria, "Data (after)Lives at the University of Pittsburgh: A Constellation Exhibition in the University Art Gallery," Contemporaneity: Historical Presence in Visual Culture 6 (2017): 36-42; https://doi.org/10.5195/contemp.2017.220. 


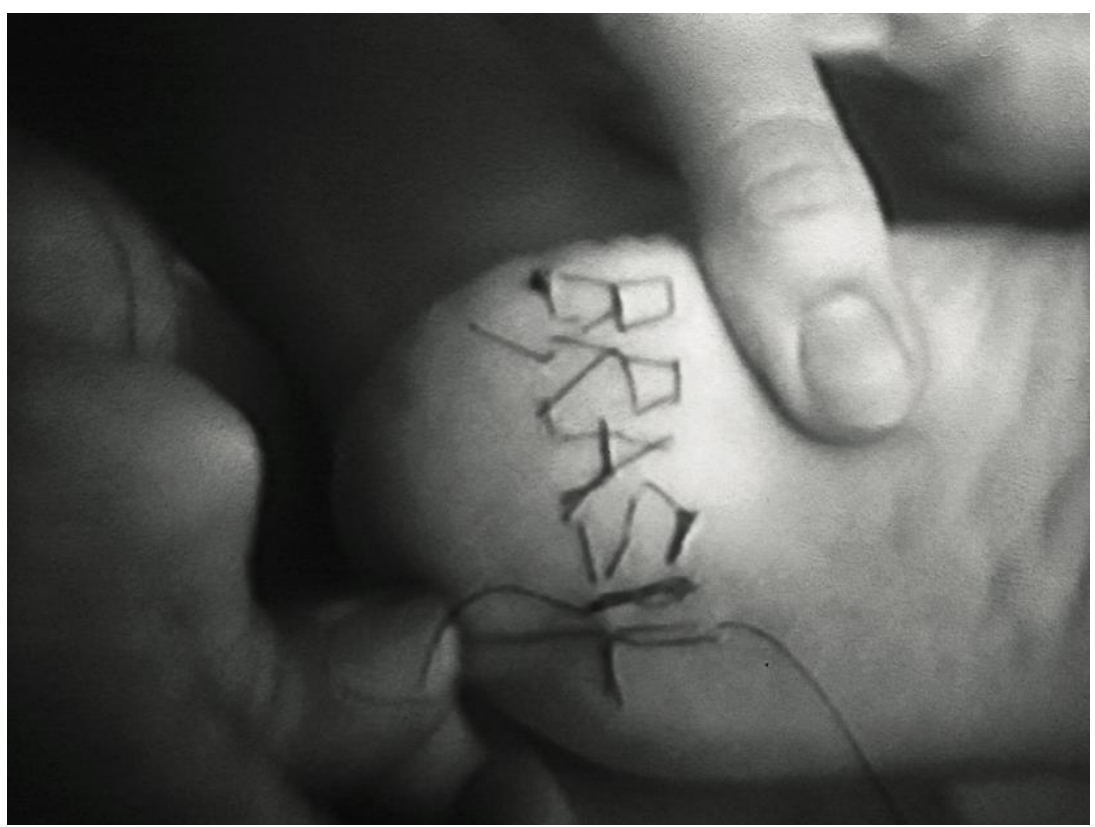

Figure 1

Letícia Parente, Marca registrada (Trademark), 1975, Video. Image courtesy of the artist's estate and Galeria Jaqueline Martins.

Shown at Video Art from Latin America among sixty other videos from 1973 to 2015, Parente's Marca registrada-her only work in this show-represented the central role of video for expressing social and political discontent as well as artists' general engagement with their local contexts, two themes reflected throughout the exhibition (Figure 1). An atrium and main gallery, the latter showcasing two video installations (José Alejandro Restrepo's Musa paradisiaca, 1996, and Gisela Motta, Leandro Lima, and Claudia Andujar's Yano-a, 2005), led to three separate rooms containing a total of six thematically organized programs, each presented as a continuous sequence. While Parente's work was featured in the program titled "Defiant Bodies," and was thus shown in dialogue with works where performance takes a central role, Marca registrada could easily have been part of any of the other programs"Economies of Labor," "The Organic Line," "Borders and Migrations," "States of Crisis," and "Memory and Forgetting"-demonstrating the transcendence of Parente's work and underscoring the fluidity of ideas and interwoven narratives of the exhibition's programs.

Marca registrada was followed by A situação (The situation, Geraldo Anhaia Mello, 1978) and paired with the 1974 series of untitled works by Sonia Andrade that played on a separate TV in a well-deserved homage to this artist. Showing Parente's work side-by-side with Mello's and Andrade's within a diachronic selection of videos (the most recent of this program being Mariana en el Cici, Mariana Jurado Rico, 2014) was an instructive gesture as it situated Parente among her closest peers in Brazil, while reflecting the exponential growth of the use of video in the region. This arrangement allowed spectators to visualize Parente's horizon of references as well as some of the themes that have remained constant across several decades, such as the display of female bodies in public and private realms.

A Sony Portapak camera (and its accompanying open reel), similar to the one Parente used, was displayed near the entrance of the gallery. This was a rare treat for visitors interested in the technology of this art form and served as an excellent reminder of the analogue nature of the equipment used by artists of Parente's generation up to the mid-1980s. The video camera was successfully paired with Videodanza "Xochimilco" (1979), by the Mexican Pola Weiss, one of the earliest videos that records the use of a portable video camera as Weiss dances with it on the street. Extending the didactics of this display, a separate room 
at the back of the gallery served as a specialized library on video art from Latin America. Built over the course of the exhibition research, and containing, for example, the most complete catalog of Parente's work to date, the library responded to the lack of regional studies on the subject and reflected this exhibition's important contribution to the history of video art from Latin America and thus to contemporary art history. The reading material was an excellent complement to the printed booklet that, structuring the six themes and labeling the entirety of works, was handed to visitors as an exhibition navigation tool. However, this library required additional time and energy from visitors engaged in an already-time-consuming exhibition, considering the temporal nature of video art.

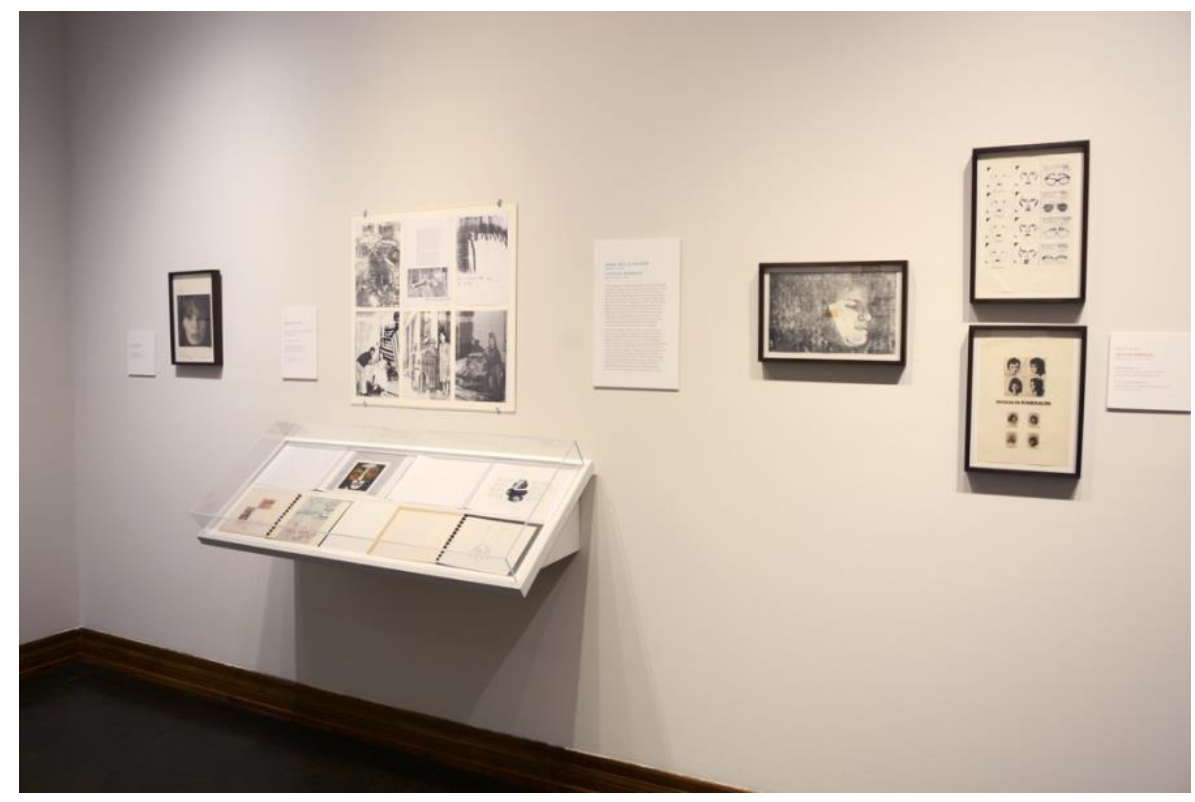

Figure 2

Xerografia: Copyart in Brazil, 1970-1990, Installation view, Robert and Karen Hoehn Family Galleries, University of San Diego. Left: Letícia Parente, Mulheres (Women), 1975; Center top and bottom: Anna Bella Geiger, Diário de um artista brasileiro (Diary of a Brazilian Artist), 1975, and História do Brasil: Little Boys and Girls (History of Brazil: Little Boys and Girls), 1975; Right: Parente, Do Not Touch and Mulheres, 1975. Photo: University of San Diego.

Similarly devoted to an artistic media closely linked to technological developments, Xerografia: Copyart in Brazil, 1970-1990 focused on the two critical decades that marked both the strongest years of dictatorial repression and the return to democracy in Brazil (Figures 26). Profusely researched, as reinforced by the catalog, the works in Xerografia were displayed chronologically in two gallery rooms, which demonstrated how Xerox art in Brazil evolved from the exclusive use of paper into different reproduction processes and media such as fax transmission and performance. Situating Parente's work outside of video art (her generally recognized niche), Xerografia revealed the rich networks that Parente partook in as part of the vibrant Brazilian art scene of the time. Works from Parente's series Mulheres (Women, 1976) stood out alongside works by Regina Silveira, Hudinilson Jr., Anna Bella Geiger, and Paulo Brusky, among a total of twenty-one artists based in São Paulo, Rio de Janeiro, and Recife who experimented with Xerox. An untitled work from Mulheres-in which Parente intervened a Xeroxed, close-up portrait of a woman with safety pins that vertically crossed her open eyes and horizontally traversed her mouth-hung on the back wall of the first room, capturing the visitor's attention as one of the few works prominently visible from the entrance of the exhibition. Meanwhile, a non-traditional self-portrait of Parente pressed against the glass of a 
Xerox machine and labeled "no touch" synthesized the representations of artists' bodies that Xerografia effectively presented as a constant thread in Brazilian Xerox art.
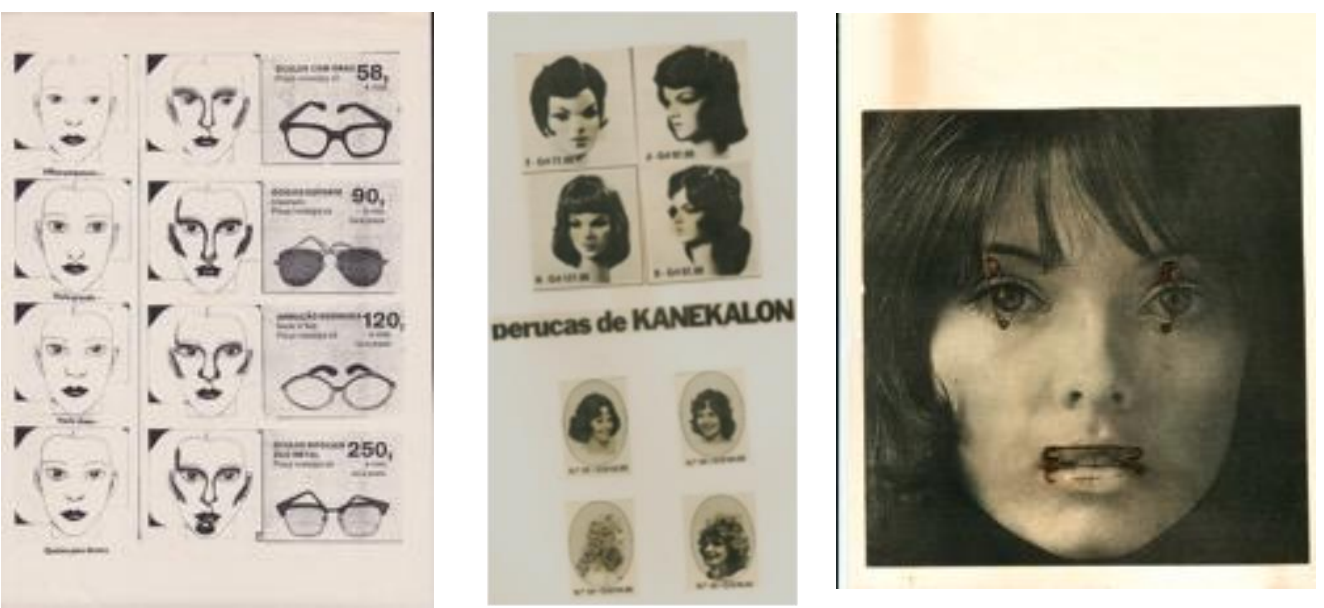

Figure 3-5

Letícia Parente, Mulheres (Women), 1976, Xerographs and mixed media on paper, dimensions variable. Image courtesy of the artist's estate and Galeria Jaqueline Martins.

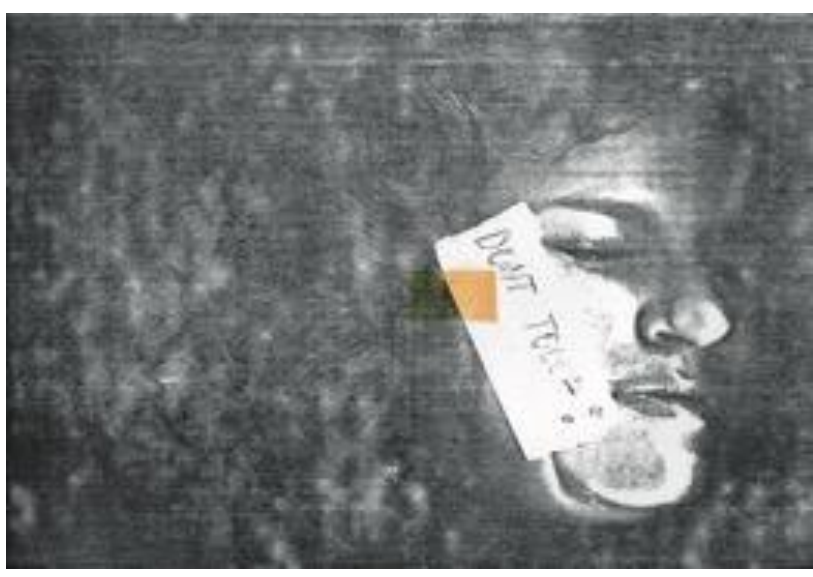

\section{Figure 6}

Letícia Parente, Don't Touch Me, n.d., Xerograph and collage on paper, $21.5 \mathrm{x}$ $34 \mathrm{~cm}$. Image courtesy of the artist's estate and Galeria Jaqueline Martins.

Focusing extensively on the use of the female body for artistic expression, Radical Women: Latin American Art, 1960-1985 brought together artists such as Lygia Pape (Brazil), Mónica Meyer (Mexico), and Victoria Santa Cruz (Peru), among many others, who photographed, manipulated, and displayed their female bodies to express their vulnerability within patriarchal societies. The exhibition featured five sections-"Mapping the Body," "Social Places," "The Power of Words," "Feminisms," and "Resistance and Fear"-and included Parente's videos Preparação I, Marca registrada (both from 1975), and Tarefa I (1982). The contribution of Parente's three videos, presented in separate gallery rooms, was to critique-humorously and, in the case of Marca registrada, painfully-the condition of women as individuals expected to be fully skilled in domestic tasks such as sewing and ironing, naturally carry an attractive appearance, and be readily available for assisting a third party, whether an individual or an institution. 


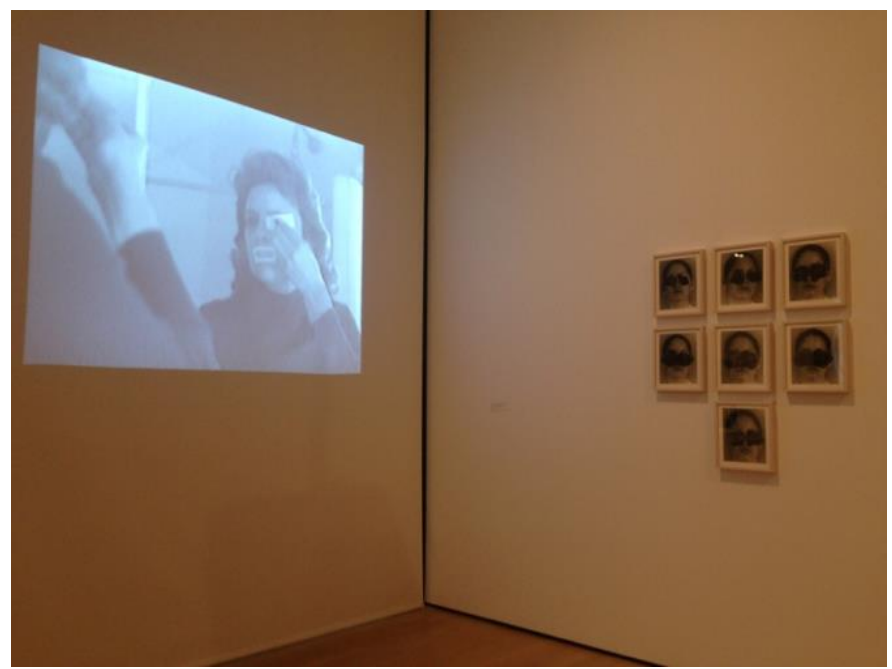

\section{Figure 7}

Radical Women: Latin American Art, 1965-1980, installation view, Hammer Museum, University of California Los Angeles. Left: Letícia Parente, Preparação I (Preparation I), 1975; Right: Rosa Navarro, Nacer y morir de una rosa (Birth and Death of Rose), 1982. Photo: Paulina Pardo Gaviria.

Seeing Parente's works among those of her peers, most of whom Parente did not know, made clear that she was far from a lone wolf in an international revolution fought, in her and others' cases, through the language of conceptual art. Her inclusion in the landmark Radical Women also underscored Parente's signature embodied artistic strategy-presenting her pinched, taped, and ironed skin as her field of resistance-and the enduring relevance of her radical work. The impressively vast exhibition, enriched by its curatorial dialogue with previous landmark exhibitions Inside the Visible: An Elliptical Traverse of 20th Century Art in, of, and from the Feminine (1996) and Wack! Art and the Feminist Revolution (2007), further benefited from its similarly extensive catalog (organized by country rather than theme) as well as from discrete, concurrent exhibitions of smaller size.

In approaching the work of Letícia Parente and other artists with comparable careers, PST: $L A / L A$ presented an ideal occasion to examine the work of a single artist through multiple curatorial frames. Through its inclusion in two focused exhibitions of largely unmapped histories and in the landmark Radical Women, Parente's work demonstrates how representations of violence can be profoundly aesthetic and moving when delivered from intimate spaces (a bare room, a bathroom, a domestic laundry area) and through the very skin of a middle-aged female citizen. Through this lens, a Xerox and a short video can prove crucial in interpreting the contemporary history of art from Latin America.

(c) $)_{\text {EY }}$ New articles in this journal are licensed under a Creative Commons Attribution 4.0 United States License.

\section{UILIS D-Sork}

This journal is operated by the University Library System of the University of Pittsburgh as part of its D-Scribe Digital Publishing Program, and is co-sponsored by the University of Pittsburgh Press. 